\title{
CORPUS Corpus
}

Archivos virtuales de la alteridad americana

Vol. 11, No. 1 | 2021

Enero / Junio de 2021

\section{Reseña de Arqueología del Mestizaje. Colonialismo y racialización, de Laura Catelli. Temuco: Ediciones UFRO-CLACSO, 2020. 296 paginas.}

Manuel Fontenla

\section{OpenEdition}

Journals

Electronic version

URL: https://journals.openedition.org/corpusarchivos/4868

DOI: 10.4000/corpusarchivos.4868

ISSN: 1853-8037

Publisher

Diego Escolar

Electronic reference

Manuel Fontenla, «Reseña de Arqueología del Mestizaje. Colonialismo y racialización, de Laura Catelli.

Temuco: Ediciones UFRO-CLACSO, 2020. 296 paginas.», Corpus [En línea], Vol. 11, №. 1 | 2021 ,

Publicado el 30 junio 2021, consultado el 03 julio 2021. URL: http://journals.openedition.org/

corpusarchivos/4868 ; DOI: https://doi.org/10.4000/corpusarchivos.4868

This text was automatically generated on 3 July 2021.

Licencia Creative Commons: Atribución-NoComercial 2.5 Argentina (CC BY-NC 2.5 AR) 


\title{
Reseña de Arqueología del Mestizaje. Colonialismo y racialización, de Laura Catelli. Temuco: Ediciones UFRO- CLACSO, 2020. 296 paginas.
}

\author{
Manuel Fontenla
}

\section{Nuevas miradas para viejos problemas: resituar la problemática del mestizaje}

1 Tanto en los ámbitos académicos, como en la producción cotidiana de "sentidos comunes", hemos visto en las últimas décadas, un definitivo ingreso de las problemáticas étnico-raciales a los debates contemporáneos. El camino de dichas problemáticas puede reconstruirse desde distintos lugares. Un largo prolegómeno, lo constituyeron las discusiones sobre indigenismo e integración, que tuvo como campo privilegiado de análisis la crítica literaria y los estudios culturales. Allí aparecieron vocabularios y conceptualizaciones críticas como la de "mestizaje" (Vasconcelos, Rojas), transculturación (Ortiz, Rama), heterogeneidad (Cornejo Polar), "literaturas alternativas" (Lienhard) y más recientemente "zona de contacto" (Pratt). Otro campo de discusiones se formó en torno a los discursos nacionalistas y a los procesos de construcción del Estado-nación a finales del XIX e inicios del XX en América Latina. Aquí el campo intelectual se amplió principalmente hacia el revisionismo historiográfico y los discursos políticos.

2 El derrotero de estas problemáticas tuvo su deriva, durante los años $80^{\prime}$ y $90^{\prime}$ del siglo pasado, por los estudios de la globalización, el multiculturalismo y las identidades políticas, más vinculado a perspectivas que borraban el lugar fundamental del conflicto, las relaciones de poder y jerarquía, en visiones celebratorias del "encuentro cultural" y un supuesto futuro de integración armónica y respetuosa de la diversidad, 
que la realidad social de las últimos cuarenta años ha mostrado sobradamente ingenua e irreal.

3 En sus distintos campos, estos debates estuvieron marcados por una categoría que fue protagonizando la discusión, a saber, la de "mestizaje"; y por un tipo específico de crítica, vinculada a los procesos de integración, asimilación y homogeneidad. En este sentido, el filósofo José Luis Grosso, afirma que el mestizaje como categoría de blanqueamiento logró hegemonizar los imaginarios raciales, convirtiendo la categoría en un lei motiv para señalar un supuesto "devenir natural" de las identidades étnicasraciales durante la época de la formación nacional. La pluralidad de categorías del uso social propias de la época colonial como las de mulato, cholo, zambo, negro e indio, cayeron bajo la simplificación y generalización homogeneizante de la categoría "mestizo" con el advenimiento de la nación.

4 No obstante, en las últimas décadas, en el contexto de cierto auge de investigaciones interdisciplinarias y en clave descolonial, y con un renovado interés en problemáticas ligadas a los procesos de subjetivación y racialización, se reactivó la mirada sobre el campo del mestizaje. Entre las propuestas más relevantes se encuentran, por ejemplo, el trabajo de Claudia Briones en Argentina con su conceptualización de "aboriginalidad", el de Marisol de la Cadena en Perú sobre los "mestizos indígenas", o los trabajos de Peter Wade tramados desde la etnografía y el análisis documental sobre las dinámicas raciales en distintos espacios de Colombia, donde la diferencia racial se ve atravesada por lo mestizo, lo indio y lo afro. 0 , incluso, tempranos trabajos desde el campo de la etnohistoria como los de Ana María Lorandi sobre mestizaje y fricciones interétnicas. Finalmente, el heterogéneo campo de debate de la colonialidad del poder y la crítica poscolonial, instalo una serie de conceptualizaciones y análisis ineludibles a la hora de pensar las problemáticas étnico-raciales: hibridez y tercer espacio (H. Bhabha), "semiosis colonial" (W. Mignolo) "borderlands" (G. Anzaldúa), Colonialidad del poder (A. Quijano).

5 Este breve y sucinto recorrido, es importante para dimensionar y ubicar la exploración que propone Laura Catelli, en su reciente libro, Arqueología del Mestizaje. Colonialidad y biopolítica (2020). En primer lugar, porque la autora propone una arqueología del concepto de mestizaje que recupera críticamente muchas de las vertientes anteriormente señaladas; y en segundo lugar, porque su particular arqueología (de factura foucaultiana y poscolonial) busca tensar el mestizaje desde la relación pasado y presente, para excavar y desenterrar (son los términos que usa) los aspectos concretos, específicos, materiales, de los mecanismos de dominación colonial que dieron lugar a las condiciones de posibilidad para la emergencia del concepto «mestizaje».

6 Esto significa, que si para los estudios clásicos, el mestizaje fue un fenómeno propio de los siglos XIX y XX, vinculado a la constitución de los estados latinoamericanos y sus identidades "nacionales", la investigación de Catelli propone un primer giro importante, a partir de un desvió epistémico-temporal que le permite distinguir dos modelos del mestizaje. Por un lado, un mestizaje que puede rastrearse desde inicios de la Conquista de América, como un dispositivo colonial, y por otro, los "discursos criollos del mestizaje" de los siglos XIX y XX. Como lo señala la autora: "Uno de mis objetivos es diferenciar y contrastar esos dos modelos de mestizaje: por un lado, el discurso del mestizaje criollo familiar como el que vemos en la foto y, por el otro, la estrategia de mestizaje colonial que alteró tan profundamente el entramado de las relaciones de poder coloniales". (p. 30) Esta distinción, le permite señalar un tipo de 
mestizaje (el mestizaje como un dispositivo biopolítico colonial) que no se circunscribe a la fundación del estado-nación, sino que se inscribe en la época de la conquista y puede ser rastreado hasta los siglos XVI y XVII. Para este rastreo, Catelli propone una metodología propia, una arqueología, nutrida de aportes foucaultianos y poscoloniales:

un quiebre conceptual que permite llevar a cabo una arqueología del concepto de mestizaje, el cual pone de relieve las estrategias, prácticas y discursos desplegados en el contexto de las relaciones de poder coloniales que contribuyeron a la estructuración jerárquica sociorracial tan característica de las sociedades latinoamericanas. Esta ruptura nos ayuda a pensar en los instrumentos y los efectos de un discurso fundamentalmente colonialista que, a partir de fines del siglo xv, buscó dominar los diversos escenarios políticos indígenas del Nuevo Mundo mediante el uso de las estrategias de alianza" (2020, p. 32)

7 No se trata entonces, de un proyecto historiográfico sobre el mestizaje, sino de una arqueología que toma la época de la conquista como punto de partida para analizar la formación del entramado heterogéneo de relaciones de poder y de lucha que el discurso del mestizaje narrará desde una perspectiva criollista y patricia, hegemónica, en el marco de la formación de los nuevos Estados-nación. A diferencia de los campos tradicionales de estudio del mestizaje, esta arqueología permite situar el mestizaje como un proceso que es parte y constitución de la colonialidad del poder: "Al comprobar y documentar mediante una arqueología la ruptura de los gestos discursivos del mestizaje colonial y el nacional, y al reconstruir los vínculos del mestizaje con la biopolítica colonial y nacional, se desarticula el olvido en el que se funda la colonialidad del poder patriarcal" (Catelli 2020, p. 34).

Esta manera de analizar el mestizaje como dispositivo colonial, no solo permite la reubicación temporal del concepto en los inicios de la conquista y como parte del imaginario racial de la colonialidad; sino también, ubica en el centro de su constitución la perspectiva de género: "una de las maneras en las que este estudio produce una diferenciación entre el mestizaje criollo y el mestizaje como estrategia de conquista es a través de un análisis con perspectiva de género que aborda el rol de las mujeres indígenas y afrodescendientes en las relaciones de poder y de lucha de la conquista, además de su centralidad simbólica en la configuración del mestizaje criollo" (Catelli 2020, p.31)

9 Bajo estas claves, la Arqueología del mestizaje que elabora Laura Catelli, propone una relectura conceptual del problema, vinculada a la constitución de la colonialidad del poder y su biopolítica racial, en el entramado de la relación racialización/sexualidad/ colonialidad como ejes de aplicación. El libro, construye desde allí, una triple potencia. En primer lugar, relee conceptual y metodológicamente los registros clásicos del campo del mestizaje como la literatura, la historiografía y los discursos nacionalistas del criollismo. En segundo lugar, propone nuevos registros y materialidades, específicamente, a través de los estudios visuales de la Pintura de Castas. Y, en tercer lugar, "arrastra" el mestizaje desde la época de la conquista hasta el presente, para mostrar sus persistencias, continuidades y ambigüedades en la constante producción de imaginarios raciales contemporáneos, desde una mirada crítica de los vínculos entre criollismo, blanquitud, patriarcado y racialización. 


\section{Clausuras epistémicas y desplazamientos críticos}

10 Dentro del minucioso estudio que presenta Catelli, donde destacan su pericia lectora (que revela los largos años de profundización en el tema), su escritura artesanal que nos transporta por el mundo de los imaginarios raciales y sus aparatos conceptuales cual si fuera una novela y no una investigación de alto voltaje teórico y metodológico, intentaré señalar dos problemáticas que, además de renovar las miradas sobre el mestizaje, permiten vincularlo con "clausuras epistémicas" que se encuentran íntimamente ligadas a las disputas actuales de la colonialidad y amplían el campo de discusión del mestizaje en otras direcciones.

11 La primera clausura epistémica refiere a las miradas sobre la blanquitud de nuestro pasado colonial, es decir, sobre nuestra relación con el imaginario del criollismo. La arqueología que propone la autora, permite pensar lo criollo, como una de las modalidades del reverso negativo del mestizaje; el criollo es "el lado oscuro" del mestizaje. En otras palabras, lo criollo como blanquitud-colonial, colabora a comprender esas identidades como la parte negada de nuestra especificidad históricoracial argentina; parte del lado negado por una modernidad colonial, eurocéntrica y patriarcal. Y para apuntar toda la importancia de este movimiento, Catelli, vincula el imaginario racial del criollo con el colonialismo interno. Específicamente, en el cuarto capítulo, titulado "La Pintura de Castas y el imaginario racial criollo", se aborda este vínculo entre colonialismo interno y agencia criolla, para dar cuenta cómo se producen ideas de raza vinculadas muy estrechamente con la ideología de limpieza de sangre. Es central, afirma Catelli, percibir el alcance que el discurso patriarcal de la pureza de sangre tiene en el imaginario racial criollo y revisar los modos complejos a través de los cuales este es instituido, o establecido, como imaginario dominante.

El análisis de la Pintura de Castas, le permite señalar cómo "la ausencia del término «criollo» en el género que analizamos parece destacar la negación criolla respecto de su propia historia de mezcla racial" (2020, p. 207), es decir, la negación de su propia blanquitud, así como su profundo prejuicio ante las castas mestizas. La ausencia del término en las pinturas torna esta negación en un aspecto constitutivo de la discursividad y la visualidad criolla.

Poner de relieve esta clausura epistémica tiene el sentido, como bien afirma Catelli, de dimensionar el enorme peso de los imaginarios raciales criollos en las dinámicas internas del espacio colonial durante las décadas inmediatamente anteriores a las gestas independentistas. Desde este punto de vista, la investigación no es exclusivamente ni reductivamente sobre "el mestizaje", es también, o mejor aún, una investigación sobre cómo estudiar críticamente los imaginarios raciales del pasado colonial. Sobre esta preocupación por el pasado colonial, se inscribe una segunda clausura epistémica.

En el clásico, White Mythologies, el teórico poscolonial Robert Young, se preguntaba por el peso de las mitologías blancas en los imaginarios imperiales y coloniales, y lo hacía desde un lugar específico. El propósito de White Mythologies, era "desarrollar una crítica epistemológica del mayor mito de Occidente: la Historia" (Young 2008, p. 199) Es decir, para Young, la principal herramienta (por no decir "arma") epistemológica de las mitologías blancas, es la Historia. Por ello, la segunda clausura epistémica que moviliza Arqueología del Mestizaje, refiere al peso epistémico de la Historia sobre los imaginarios raciales. Esto significa, que si, por un lado, encontramos un complejo y renovado 
análisis de los imaginarios raciales específicos del mestizaje, por otro, el libro de Catelli, también señala posibilidades, vías, metodologías y analíticas, para construir epistemes críticas desde las cuales leer a contrapelo la historia racial de nuestro pasado colonial.

Uno de los puntos destacados en esta crítica de las representaciones del pasado colonial, se da a partir del diálogo con Michel Foucault. El tercer capítulo de Arqueología del Mestizaje ubica su análisis en discursos históricos del siglo XVI y XVII, sobre los cuales Catelli se pregunta respecto del mestizo, “¿Qué lugares ocupará en el discurso de la historia? ¿Cuáles serán sus estrategias de poder?” (p. 149) Para desandar estas preguntas, la autora reelabora la distinción entre los modos historiográficos que Foucault llama el discurso histórico y la contrahistoria.

El discurso histórico es aquel que "al contar la historia, la historia de los reyes, los poderosos, los soberanos y sus victorias [...] trata de vincular jurídicamente a los hombres al poder mediante la continuidad de la ley, que se pone de relieve dentro de ese poder y en su funcionamiento [...] se trata también de fascinarlos con la intensidad, apenas tolerable, de la gloria, de sus ejemplos y sus hazañas. El yugo de la ley y el brillo de la gloria me parecen las dos caras mediante las cuales el discurso histórico aspira a suscitar cierto efecto de fortalecimiento del poder" (citado en Catelli 2020, p. 155)

Frente a este discurso, Foucault definía la contrahistoria como:

la historia de la lucha de la guerra de razas, es una contrahistoria, [...] esta contrahistoria no sólo disocia la unidad de la ley soberana que obliga, sino que, por añadidura, fractura la continuidad de la gloria. Pone de relieve que la luz -ese famoso deslumbramiento del poder- no es algo que petrifica, solidifica, inmoviliza al cuerpo social en su totalidad, y por consiguiente lo mantiene en el orden, sino que, en realidad, es una luz que divide, ilumina de un lado pero deja en la sombra o expulsa a la noche otra parte del cuerpo social. Y la historia, la contrahistoria que nace con el relato de la lucha de razas, va a hablar precisamente del lado sombrío, a partir de esa sombra. Va a ser el discurso de quienes no poseen la gloria o de quienes la han perdido y ahora se encuentran, quizás transitoriamente pero sin duda durante largo tiempo, en la oscuridad y el silencio" (Citado en Catelli, 2020, p. 148)

La distinción foucaultiana no tiene por objeto simplemente identificar el discurso histórico con, por ejemplo, el discurso de la historia "oficial" y el de la "contrahistoria" con la historia de los vencidos o la historia subalterna. El interés de la distinción, le permitía al pensador francés, analizar cómo la articulación poder-saber funciona en cada una de ellas. Pero si bien para Foucault esta distinción alcanza para desmontar la lógica del poder en la historia de Europa, al introducir la dimensión y la historia de la colonialidad, la misma nos resulta insuficiente. Y aquí es donde Catelli realiza su intervención: "Es justamente en esa caracterización binaria donde se abre el espacio que he llamado entrelugar de la historia, en el cual se articulan los discursos y las agencias de los mestizos" (p.158).

Si bien la distinción entre discurso histórico y contrahistoria es potente para analizar la dimensión del poder en la historia, no deja lugar para la especificidad de la historia de la colonialidad, donde el mestizo ocupa un lugar central. Por ello, la autora construye este "entrelugar de la historia" para señalar un "espacio de poder que está determinado por una ambivalencia irreductible" y que a la vez "hace visible el entretejido de las relaciones de poder coloniales" (p. 158). A contrapelo del discurso homogeneizante del mestizaje blanqueador, aparece la posibilidad de otros discursos del mestizaje, posibles 
de leerse como entrelugar de la historia, en esta clave de "tercer espacio", en los conceptos de "ambivalencia, repulsión y apropiación".

Poner el acento analítico en estos procesos de ambivalencia, permite contrarrestar y dar cuenta de un problema no menor, que presenta dos caras. De un lado, la tendencia generalizada a subestimar o a reducir la complejidad de los procesos de racialización o etnicización que produjo la dominación colonial, y del otro, el resguardo a la esencialización o fijación de procesos identitarios cuya continuidad ha sido negada.

Por ello, una de las claves de la arqueología propuesta, es que no descuida las dimensiones temporales y subjetivas de las relaciones de poder coloniales, sino que, parte del análisis de la dominación y el control de los cuerpos y va hacia las prácticas de poder, de lucha, resistencia y supervivencia en distintos espacios y tiempos.

\section{Lo colonial intempestivo}

21 Más allá y más acá del espacio-tiempo latinoamericano, lo colonial persiste en el sentido intempestivamente nietzscheano. Lo colonial, actúa en contra del tiempo al que pertenece, no para negar un pasado consagrado, no para sumergirse en un presente deshistorizado, no para buscar los orígenes de un problema, no para trazar la teleología de sus soluciones. A contrapelo de esas lógicas modernas y coloniales, en Arqueología del mestizaje, Laura Catelli, sitúa lo colonial, justamente, en una crítica de la historicidad del presente que articula lo temporal y lo epistémico. Su construcción de la problemática, sus modos de abordaje, los sentidos que pone en tensión, ubica a los imaginarios raciales, mestizos y criollos, como parte de las disputas actuales que atraviesan Latinoamérica, para insistir en que "las asimetrías, las injusticias y los abusos del colonialismo persisten ocultos en intersticios de los imaginarios sociales e identitarios que el dispositivo de mestizaje contribuyó a configurar y naturalizar" ( $p$. 268).

22 Ante la persistencia de lo colonial, este libro, renueva los intentos por construir perspectivas críticas sobre los imaginarios históricos de un pasado racial que no deja de irrumpir en el presente, y sobre el cual es necesario seguir señalando las obturaciones problemáticas que producen los metarrelatos identitarios, como el mestizaje, y los modos complejos en que estos pueden tornarse funcionales a la persistencia de la colonialidad del poder.

\section{BIBLIOGRAPHY}

Grosso, J. L. (2008). Indios Muertos, Negros Invisibles. Hegemonía, Identidad y Añoranza. Córdoba: Encuentro Grupo Editor.

Szurmuk, M; Mckee, R (coords) (2009). Diccionario de estudios culturales latinoamericanos. México: Siglo XXI Editores. 
Young, R. (2008). Nuevo recorrido por las mitologías blancas. En Mezzadra, S y Rahola, F. (Comps) Estudios Postcoloniales. Ensayos Fundamentales. (pp. 197-238) Madrid: Traficantes de Sueños.

\section{AUTHOR}

MANUEL FONTENLA

Universidad Nacional de Catamarca y

Consejo Nacional de Investigaciones Científicas y Técnicas, Argentina.

Correo electrónico: mfontenla@huma.unca.edu.ar 